\title{
Water and beverage consumption among adults in the United States: cross-sectional study using data from NHANES 2005-2010
}

\author{
Adam Drewnowski ${ }^{1,2^{*}}$, Colin D Rehm² and Florence Constant ${ }^{3}$
}

\begin{abstract}
Background: Few studies have examined plain water consumption among US adults. This study evaluated the consumption of plain water (tap and bottled) and total water among US adults by age group (20-50y, 51-70y, and $\geq 71 y)$, gender, income-to-poverty ratio, and race/ethnicity.

Methods: Data from up to two non-consecutive 24-hour recalls from the 2005-2006, 2007-2008 and 2009-2010 National Health and Nutrition Examination Survey (NHANES) was used to evaluate usual intake of water and water as a beverage among 15,702 US adults. The contribution of different beverage types (e.g., water as a beverage [tap or bottled], milk [including flavored], 100\% fruit juice, soda/soft drinks [regular and diet], fruit drinks, sports/energy drinks, coffee, tea, and alcoholic beverages) to total water and energy intakes was examined. Total water intakes from plain water, beverages, and food were compared to the Adequate Intake (Al) values from the US Dietary Reference Intakes (DRI). Total water volume per 1,000 kcal was also examined.

Results: Water and other beverages contributed $75-84 \%$ of dietary water, with $17-25 \%$ provided by water in foods, depending on age. Plain water, from tap or bottled sources, contributed $30-37 \%$ of total dietary water. Overall, 56\% of drinking water volume was from tap water while bottled water provided $44 \%$. Older adults ( $\geq 71 \mathrm{y}$ ) consumed much less bottled water than younger adults. Non-Hispanic whites consumed the most tap water, whereas Mexican-Americans consumed the most bottled water. Plain water consumption (bottled and tap) tended to be associated with higher incomes. On average, younger adults exceeded or came close to satisfying the DRIs for water. Older men and women failed to meet the Institute of Medicine (IOM) Al values, with a shortfall in daily water intakes of $1218 \mathrm{~mL}$ and $603 \mathrm{~mL}$ respectively. Eighty-three percent of women and $95 \%$ of men $\geq 71 \mathrm{y}$ failed to meet the IOM Al values for water. However, average water volume per 1,000 kcal was 1.2-1.4 L/1,000 kcal for most population sub-groups, higher than suggested levels of $1.0 \mathrm{~L} / 1.000 \mathrm{kcal}$.
\end{abstract}

Conclusions: Water intakes below IOM-recommended levels may be a cause for concern, especially for older adults.

Keywords: Water intake, Drinking water, Adequate hydration, Adults, Beverages, Dietary surveillance

\section{Background}

Drinking plain water is an effective way to provide adequate hydration without calories [1,2]. Drinking plain water, tap or bottled, instead of caloric beverages, helps to reduce dietary energy density and may contribute to the management of body weight [3-8]. Water from

\footnotetext{
* Correspondence: adamdrew@uw.edu

'Université Pierre et Marie Curie - Paris VI, Groupe Hospitalier Pitié-Salpêtrière,

47 boulevard de l'Hopital, Paris 75013, France

${ }^{2}$ Center for Public Health Nutrition, University of Washington, Box 353410,

Seattle, WA 98195, USA

Full list of author information is available at the end of the article
}

beverages and foods is the key determinant of the energy density of the diet [9].

Adequate intakes (AI) for water are defined on the basis of three factors: observed water intakes in population groups, desirable water volumes per energy intake, and desirable osmolality values in urine or plasma [10-12]. The AI values for water from beverages and foods according to the US Institute of Medicine (IOM) are $2700 \mathrm{~mL} /$ day for adult women and $3700 \mathrm{~mL} /$ day for adult men [13]. These values were based on median intake estimates among younger adults from NHANES III.

\section{Biomed Central}


The desirable water-to-energy ratio is another index of adequate hydration. In the US, the IOM Dietary Reference Intake (DRI) Subcommittee suggested the standard water requirement for adults at $1.0 \mathrm{~L}$ per $1,000 \mathrm{kcal}$ of energy expenditure [13]. This value could be increased to $1.5 \mathrm{~L} /$ $1,000 \mathrm{kcal}$, depending on activity level and water loss. Guidelines issued by the European Food Safety Authority (EFSA) [10] specify that the total available water intakes for adults should be no less than $1.0 \mathrm{~L} / 1,000 \mathrm{kcal}$.

The established DRI values for water are based on water obtained from drinking water (tap and bottled); water from other caloric and non-caloric beverages, and on moisture from foods $[10,13]$. The DRIs were established by the IOM mostly to prevent the adverse effects of dehydration, and the IOM report indicates that considerable inter-individual variation exists in terms of necessary amounts of water to be consumed. Beyond issues of hydration, previous studies have shown that plain water consumption was associated with higher quality diets, better health behaviors, and lower risk for chronic disease in youth and adults [7,14-16].

With some exceptions $[15,17,18]$, few studies have explored the consumption of plain water among nationally representative samples of US adults. To our knowledge, no studies have examined water intake using the most recently available dietary data. In addition, previous work has not broken down water consumption by beverage category. The present study was conducted using a large and nationally representative database: National Health and Nutrition Examination Survey (NHANES) 2005-2010 for adults $\geq 20 y$. Estimates of total dietary water from all sources (including plain water) from other beverages and from moisture in foods were compared to the IOM AI values. Additional analyses examined the contribution of different beverages to overall water and energy intakes. Lastly, we evaluated the water/calorie ratios $(\mathrm{mL} / 1,000 \mathrm{kcal})$ and compared them to the recommended values.

\section{Methods}

\section{Dietary intake databases}

The present analyses used data from three cycles of the nationally representative National Health and Nutrition Examination Survey (NHANES), corresponding to years 2005-2006, 2007-2008 and 2009-2010. The National Center for Health Statistics (NCHS) has obtained IRB approval for all cycles of NHANES studies [19] and the data has been made available for public use via the NCHS website [20]. The three NHANES cycles provided us with a nationally representative sample of 15,702 adults age $\geq 20 y$.

These NHANES cycles were selected for two reasons. First, the collection of data on tap and bottled water consumed as a beverage only began in 2005 as part of the 24-h recall. In previous NHANES cycles, information about water as a beverage was not collected during the recall, but was assessed via questionnaire after the 24-h recall was complete. Second, the 2005-10 NHANES cycles included two 24-h recalls for most respondents, allowing for estimation of usual intakes using methods developed by the National Cancer Institute (NCI). The first recall was conducted by trained dietary interviewers in a mobile examination center while the second recall was conducted by telephone some days later [21-24].

\section{Plain water and beverage consumption}

Beverages were classified into nine broad groups: Water (bottled or tap), milk (including flavored), fruit juice (100\%), soda/soft drinks (regular and diet), fruit drinks, sports/energy drinks, coffee, tea, and alcoholic beverages.

The NHANES 24-h recalls for each respondent provide information on the amount in grams of each food and beverage consumed. All results presented are for $\mathrm{mL}$ of water content from selected beverages, not mean intakes by volume (e.g., we present $\mathrm{mL}$ of water in milk, not $\mathrm{mL}$ of milk consumed), as that information is not provided in the NHANES data.

\section{Energy intakes from beverages and foods}

Energy intakes from different beverages and foods were estimated for each respondent. Food and beverage amounts were converted to calories (kilocalories [kcal]) using standard procedures for the United States Department of Agriculture Food and Nutrient Database for Dietary Studies.

\section{Statistical analyses}

We used the National Cancer Institute (NCI) Method to characterize the usual intake distribution of total water, water consumed as a beverage (e.g., tap and water), and water and energy from beverage categories $[25,26]$. Two different approaches have been previously developed to estimate usual intake distributions using the NCI method: one for consumption of a ubiquitously consumed dietary component (e.g., calcium or total grains) and one for episodically consumed components (e.g., vitamin A or whole grains). The ubiquitous model fits a one-part nonlinear mixed model that incorporates only the amount consumed into the estimation of usual intake, while the episodic model fits a two-part mixed model that incorporates both the probability of consumption and the amount consumed in estimating the usual intake distribution. For total water, water from all beverages and water from food sources, the model appropriate for ubiquitously consumed dietary components was employed. All other values were estimated using the episodic model. For example, tap water was consumed by only $67 \%$ of respondents while less than half the respondents consumed bottled water on their first recall. For no beverage type and in no subpopulation of interest did the frequency of consumption approach 90-95\%, which would justify using the ubiquitous 
model. Additional covariates were included in the model to account for whether the recall data was from a weekday or weekend and whether it was the first or second recall $[25,26]$.

In order to account for the complex survey design of NHANES data and estimate standard errors, balanced repeated replication (BRR) weights were constructed using WesVar software (Westat, Rockville, MD, 2012). A Fay's adjustment of 0.7 was used and a total of 48 BRR runs were repeated for each analysis. The results are representative of the usual intake of the US population or sub-population of interest.

Because the NCI Method employs a random seed in running the models, values that would otherwise be expected to sum together may not do so (i.e., repeated runs of the same model can result in differences of $\sim 1 \%$ between runs). Therefore, the sum of estimates of water or energy from specific beverage categories will not be expected to sum perfectly to the global estimate of total water intake. For example, the estimated mean value of total water consumed as a beverage was $1138 \mathrm{~mL}$, while the estimate for tap and bottled water respectively was $644 \mathrm{~mL}$ and $502 \mathrm{~mL}$, summing to $1146 \mathrm{~mL}$. In estimating the population proportion of each beverage type to water and energy intakes, these estimates were obtained by dividing the category-specific value by the sum of all category-specific values. The population proportion is the percent total water or energy from specific beverage categories at the population-level. This measure can be interpreted as a ratio of the means, rather than a mean of the ratios, and is best suited for examinations of population-level dietary habits [27]. When the estimated relative standard error was greater than 30\% for estimated means the results are not presented.

All analyses accounted for the complex survey design of NHANES and reflect the dietary behaviors of the US adult population from 2005-2010. The usual intake of water consumed as a beverage and total water were evaluated overall and by age group, gender, race/ethnicity, and family income-to-poverty ratio. The age groups were $20-50 y, 51-70 y$, and $\geq 71 y$. Race/ethnicity was defined by self-report as non-Hispanic white, non-Hispanic black, Mexican-American, other Hispanic and mixed race/other. Family income-to-poverty ratios were defined as $<1.0$, $1.0-1.99,2.0-3.49$, and $\geq 3$.

T-tests with unequal variances were used to test for differences in the mean intake level in each sub-group related to a reference group of interest. The reference groups used were age 20-50y, men, non-Hispanic whites, and those with a family income-to-poverty ratio $\geq 3.5$.

All analysis used SAS software (Version 9.4 of SAS System for Windows, SAS Institute, Cary, NC, 2013) and estimates of the usual intake distribution used macros, code and methods adapted from NCI and the Centers for Disease Control (CDC) [28,29].

\section{Results}

\section{Plain water consumption}

Data presented in Table 1 show the consumption of plain water (total) in $\mathrm{mL}$ by age and by socio-demographic group. About $78 \%$ of adults reported consuming either tap or bottled water as a beverage on their first 24-hour recall.

On average, American adults consumed 1.1 L (1,138 mL) of water as a beverage per day. Older adults $(\geq 71 \mathrm{y})$ consumed less water than younger adults. Overall, men and women consumed comparable amounts of water as a beverage.

There was a strong effect of socioeconomic status on consumption of water as a beverage. Adults with higher incomes consumed more water as a beverage than adults with lower incomes. There was no marked difference by race/ethnicity, though the other race/mixed race group consumed the most water as a beverage.

Additional data from Table 1 show consumption of tap versus bottled water by age, gender, race/ethnicity, and family income-to-poverty ratio. Overall, adults consumed $644 \mathrm{~mL} / \mathrm{d}$ of tap water (about $56 \%$ of total water consumed as a beverage) and $502 \mathrm{~mL} / \mathrm{d}$ of bottled water (44\%).

The patterns of water consumption varied strongly with age. For bottled water, consumption was strongly related to age; with younger adults consuming much more bottled water than older adults. The effect of gender on bottled/tap water consumption was not statistically significant.

There were strong socio-demographic effects on type of water consumed. Non-Hispanic whites consumed the most tap water and the least bottled water $(703 \mathrm{~mL} / \mathrm{d}$ from tap vs. $437 \mathrm{~mL} / \mathrm{d}$ from bottled). By contrast, Mexican Americans consumed the most bottled water $(729 \mathrm{~mL} / \mathrm{d}$ from bottled vs. $383 \mathrm{~mL} / \mathrm{d}$ from tap). Lower-income adults consumed $603 \mathrm{~mL} / \mathrm{d}$ of tap water as opposed to $721 \mathrm{~mL} / \mathrm{d}$ for higher income adults. There was a strong effect of family income on consumption of tap water. For bottled water, compared to adults with higher family incomes, only those with the lowest family incomes consumed significantly less bottled water.

\section{Water intakes from plain water, beverages, and foods}

Table 2 summarizes the principal sources of total dietary water by age group. The principal beverage sources were plain water, soda, coffee, tea, milk, and alcohol, followed by fruit drinks and fruit juices. Since milk was often used with cereal, results are presented for milk (total) and for milk consumed as a beverage (i.e. not with cereal). Additional water was provided in the form of moisture from foods.

The contribution of plain water, soda (regular and diet), alcohol and fruit drinks to water intakes tended to decrease with age. By contrast, the contribution of coffee and tea to total water intake increased with age. Older adults $(\geq 71 \mathrm{y})$ obtained about $18 \%$ of their daily water 
Table 1 Mean intakes ${ }^{1}$ of plain, tap and bottled water $(\mathrm{mL})$ among adults by socio-demographic group

\begin{tabular}{|c|c|c|c|c|c|c|c|}
\hline & $\mathrm{n}$ & $\begin{array}{c}\text { Total water } \\
\text { as a beverage }\end{array}$ & $\begin{array}{l}\text { Pairwise } \\
\text { p-value }\end{array}$ & Tap water & $\begin{array}{l}\text { Pairwise } \\
\text { p-value }\end{array}$ & Bottled water & $\begin{array}{l}\text { Pairwise } \\
\text { p-value }\end{array}$ \\
\hline All Adults & 15702 & $1138(16)$ & - & $644(13)$ & - & $502(13)$ & - \\
\hline \multicolumn{8}{|l|}{ Age group } \\
\hline $20-50$ & 8389 & $1294(22)$ & ref & $700(17)$ & ref & $597(16)$ & ref \\
\hline $51-70$ & 4737 & $1020(20)$ & $<0.001$ & $607(18)$ & $<0.001$ & $431(14)$ & $<0.001$ \\
\hline$\geq 71$ & 2576 & $669(12)$ & $<0.001$ & $495(10)$ & $<0.001$ & $181(9)$ & $<0.001$ \\
\hline \multicolumn{8}{|l|}{ Gender } \\
\hline Men & 7614 & $1153(23)$ & 0.30 & $660(15)$ & 0.12 & 509 (19) & 0.73 \\
\hline Women & 8088 & 1125 (14) & ref & $628(14)$ & ref & $501(12)$ & ref \\
\hline \multicolumn{8}{|l|}{ Race/ethnicity } \\
\hline Non-Hispanic White & 7610 & $1134(19)$ & ref & $703(17)$ & ref & $437(12)$ & ref \\
\hline Non-Hispanic Black & 3173 & $1129(23)$ & 0.87 & $513(18)$ & $<0.001$ & $617(27)$ & $<0.001$ \\
\hline Mexican-American & 2899 & $1095(25)$ & 0.23 & $383(22)$ & $<0.001$ & $729(33)$ & $<0.001$ \\
\hline Other Hispanic & 1322 & $1208(41)$ & 0.10 & $455(35)$ & $<0.001$ & $758(48)$ & $<0.001$ \\
\hline Other race - including mixed race & 698 & $1314(96)$ & $<0.001$ & $692(60)$ & 0.86 & $606(37)$ & $<0.001$ \\
\hline \multicolumn{8}{|l|}{ Family income-to-poverty ratio } \\
\hline$<1$ & 2905 & $1026(33)$ & $<0.001$ & $603(28)$ & $<0.001$ & $407(21)$ & $<0.001$ \\
\hline $1-1.99$ & 3870 & $1088(25)$ & $<0.001$ & $565(22)$ & $<0.001$ & $542(25)$ & 0.27 \\
\hline $2-3.49$ & 3181 & $1115(27)$ & $<0.001$ & $625(22)$ & $<0.001$ & $505(16)$ & 0.86 \\
\hline$\geq 3.5$ & 4532 & $1223(20)$ & ref & $721(17)$ & ref & $509(17)$ & ref \\
\hline
\end{tabular}

${ }^{1}$ Values are survey-weighted means with standard errors in parentheses.

Table 2 Mean and percent of total water $(\mathrm{mL})$ from various food/beverage categories by age group

\begin{tabular}{|c|c|c|c|c|c|c|}
\hline & \multicolumn{2}{|c|}{$20-50 y$} & \multicolumn{2}{|c|}{$51-70 y$} & \multicolumn{2}{|c|}{$\geq 71 y$} \\
\hline & Mean (SE) & $\%$ of total water & Mean (SE) & $\%$ of total water & Mean (SE) & $\%$ of total water \\
\hline Water & $1294(22)$ & 37.1 & $1020(20)$ & 32.0 & $669(12)$ & 30.1 \\
\hline Soda & $466(9)$ & 13.4 & $312(8)$ & 9.8 & $140(5)$ & 6.3 \\
\hline Diet soda & $164(4)$ & 4.7 & $178(6)$ & 5.6 & $62(3)$ & 2.8 \\
\hline Regular soda & $310(8)$ & 8.9 & $135(3)$ & 4.2 & $79(3)$ & 3.6 \\
\hline Coffee & $297(6)$ & 8.5 & $515(11)$ & 16.2 & $406(8)$ & 18.3 \\
\hline Alcohol & $280(9)$ & 8.0 & $156(6)$ & 4.9 & $50(3)$ & 2.3 \\
\hline Milk & $142(4)$ & 4.1 & $137(4)$ & 4.3 & $153(4)$ & 6.9 \\
\hline Milk (no cereal) & $111(4)$ & 3.2 & $108(4)$ & 3.4 & $106(3)$ & 4.8 \\
\hline Tea & $197(5)$ & 5.6 & $292(7)$ & 9.2 & $158(6)$ & 7.1 \\
\hline Fruit drinks & $90(3)$ & 2.6 & $74(4)$ & 2.3 & $32(2)$ & 1.4 \\
\hline Diet fruit drinks & $16(2)$ & 0.5 & $36(3)$ & 1.1 & $13(2)$ & 0.6 \\
\hline Regular fruit drinks & $74(3)$ & 2.1 & $38(3)$ & 1.2 & $19(2)$ & 0.9 \\
\hline Fruit juice & $74(3)$ & 2.1 & $59(2)$ & 1.8 & $59(2)$ & 2.7 \\
\hline Sports/energy & $54(3)$ & 1.5 & $24(2)$ & 0.7 & $6(1)$ & 0.3 \\
\hline Water from food & $590(5)$ & 16.7 & $598(11)$ & 18.3 & $547(11)$ & 24.4 \\
\hline Water from beverages ${ }^{1}$ & $2940(20)$ & 83.3 & $2665(23)$ & 81.7 & $1693(15)$ & 75.6 \\
\hline Total daily water & $3563(24)$ & - & $3229(27)$ & - & $2251(17)$ & - \\
\hline
\end{tabular}

${ }^{1}$ Milk consumed with food is included as a beverage. 
from coffee and coffee beverages compared to $8.5 \%$ among younger adults.

Among adults aged $20-50 y, 83 \%$ of total water came from beverages, including $37 \%$ from plain water, and $17 \%$ from moisture in foods. For this age group, soda was an important source of dietary water, accounting for $13 \%$ of total water. Coffee and alcohol respectively provided $8.5 \%$ and $8 \%$ of total water.

Among adults aged $51-70 \mathrm{y}, 82 \%$ of total water came from beverages, including $32 \%$ from plain water, and $18 \%$ from moisture in foods. For this age group, soda provided $10 \%$ of total water, whereas coffee provided $16 \%$ and tea another $9 \%$. Alcohol provided $5 \%$ of total water.

Among adults aged $\geq 71,76.0 \%$ of total water came from beverages, including $30 \%$ from plain water. Twenty-seven percent of water came from moisture in foods. For this age group, soda provided $6 \%$ of total water, whereas coffee provided $18.0 \%$ and tea another $7 \%$. Alcohol provided only $2.0 \%$ of total water for this age group.

Figure 1 shows the principal sources of total dietary water separately by gender and age group. For both men and women, the principal beverage sources were plain water, soda, coffee, tea, milk, and alcohol. The age-related decrease in soda and alcohol consumption and increase in coffee consumption were observed for both men and women.

The shortfall in water consumption relative to the IOM AI values for each age group is also indicated in Figure 1. It can be seen that as a group, older men failed to meet the AI value. The shortfall amount for that group was $1,218 \mathrm{~mL} / \mathrm{d}$ for men $\geq 71$. On average, women aged $\leq 70 \mathrm{y}$ exceeded the AI value, whereas women $\geq 71 \mathrm{y}$ had a shortfall of approximately $603 \mathrm{~mL} / \mathrm{d}$. Among adults 20-50y $42.7 \%$ of men and $40.6 \%$ of women failed to meet the IOM AI value for total water $(3700 \mathrm{~mL}$ for men and $2700 \mathrm{~mL}$ for women). For adults $51-70 y, 59.1 \%$ of men and $44.9 \%$ of women failed to meet the AI value for total water. Ninetyfive percent (94.7\%) of men and $82.6 \%$ of women aged $\geq 71 \mathrm{y}$ failed to meet the AI value for water.

\section{Energy intakes from beverages and foods}

Table 3 shows the contribution to energy intakes from beverages and foods by age group. The beverages are separated by category. The contribution of foods to energy intakes rose with age, from $78.3 \%$ among younger adults to $86.3 \%$ among those $\geq 71 \mathrm{y}$. The contribution of beverages to energy intakes declined from $21.7 \%$ among $20-50 y$ to $13.7 \%$ among $\geq 71 y$. Soda accounted for $5.7 \%$ of energy intakes in the 20-50y age group but only $2.1 \%$ among those $\geq 71 y$.

\section{Water density per 1,000 calories}

Total water intakes and water density per $1,000 \mathrm{kcal}$ is shown in Table 4. The observed water volume per $1,000 \mathrm{kcal}$ was between 1.2-1.4 L/1,000 kcal. Adults 50$70 y$, women, non-Hispanic whites and adults with higher incomes consumed the most water dense diets.

\section{Discussion}

These analyses of total water intakes from all sources, including tap and bottled water, were conducted among a representative sample of US adults from the NHANES 2005-2010 database. The amounts of dietary water provided by plain water and by other beverages and foods were then

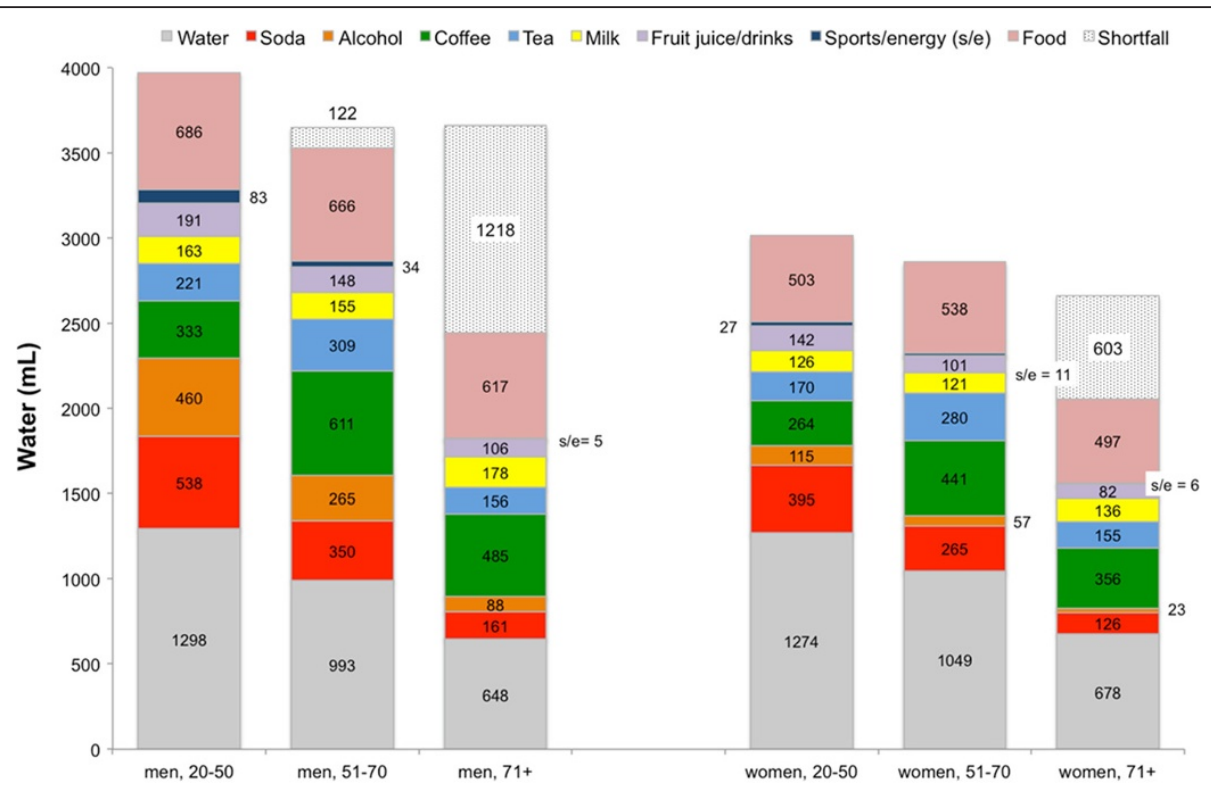

Figure 1 Water intakes from beverage/food category by age and gender among US adults. 
Table 3 Mean and percent of total energy (kcal) from various food/beverage categories by age group

\begin{tabular}{|c|c|c|c|c|c|c|}
\hline & \multicolumn{2}{|c|}{$20-50 y$} & \multicolumn{2}{|c|}{$51-70 y$} & \multicolumn{2}{|c|}{$\geq 71 y$} \\
\hline & $\begin{array}{c}\text { Mean } \\
\text { (SE) }\end{array}$ & $\begin{array}{l}\% \text { of } \\
\text { total }\end{array}$ & $\begin{array}{c}\text { Mean } \\
(\mathrm{SE})\end{array}$ & $\begin{array}{l}\% \text { of } \\
\text { total }\end{array}$ & $\begin{array}{c}\text { Mean } \\
(\mathrm{SE})\end{array}$ & $\begin{array}{l}\% \text { of } \\
\text { total } \\
\end{array}$ \\
\hline Milk & $90(2)$ & 3.6 & $83(2)$ & 3.9 & $87(2)$ & 5.1 \\
\hline Milk (no cereal) & $74(2)$ & 3.0 & $66(2)$ & 3.2 & $63(2)$ & 3.7 \\
\hline Soda & $141(4)$ & 5.7 & $73(2)$ & 3.5 & $35(2)$ & 2.1 \\
\hline Alcohol & $151(4)$ & 6.1 & $82(3)$ & 3.9 & 35 (3) & 2.1 \\
\hline Fruit juice & $39(2)$ & 1.6 & $31(1)$ & 1.5 & $31(1)$ & 1.8 \\
\hline Fruit drink & $40(2)$ & 1.6 & $19(1)$ & 0.9 & $12(1)$ & 0.7 \\
\hline Tea & $25(1)$ & 1.0 & $20(1)$ & 1.0 & $8(1)$ & 0.5 \\
\hline Coffee & $8(1)$ & 0.3 & $8(1)$ & 0.4 & $6(1)$ & 0.4 \\
\hline Sports/energy & $16(2)$ & 0.6 & $6(1)$ & 0.3 & * & $*$ \\
\hline Water & - & - & - & - & - & - \\
\hline $\begin{array}{l}\text { Energy from } \\
\text { beverages }\end{array}$ & $526(6)$ & 21.7 & $351(4)$ & 17.0 & $225(4)$ & 13.7 \\
\hline $\begin{array}{l}\text { Energy from } \\
\text { food }^{1}\end{array}$ & 1901 (12) & 78.3 & $1716(12)$ & 83.0 & 1419 (12) & 86.3 \\
\hline Total energy & 2437 (13) & - & 2061 (14) & - & $1643(13)$ & - \\
\hline
\end{tabular}

*Relative standard error is greater than $30 \%$

${ }^{1}$ Milk consumed with food is included as a beverage.

compared to AI values by gender and by age group. The intent was to examine how close the population came to meeting the AI values, as defined by the IOM DRIs. According to the IOM, AI values may be used as goals for individual intakes though there is much inter-individual variation for water needs. Health status, physical activity or strenuous work, and environmental factors, such as temperature and humidity, are additional aspects to be considered when evaluating adequate intakes at the individual level [2,13,30-32].

A large proportion of older men (94.7\%) and women (82.6\%) failed to meet the IOM AI values. The average shortfall was $1218 \mathrm{~mL}(41.2 \mathrm{fl} \mathrm{oz})$ for older men and $603 \mathrm{~mL}(20.4 \mathrm{fl} \mathrm{oz}$ ) for older women. The average shortfall was only $122 \mathrm{~mL}$ ( $4.1 \mathrm{fl} \mathrm{oz}$ ) for men $50-70$, though $59.1 \%$ consumed less than $3700 \mathrm{~mL}$ per day. Although the average intake of water among women less than 70 was adequate; $45 \%$ and $41 \%$ of women $51-70 y$ and $20-50 y$ consumed less than $2700 \mathrm{~mL}$ of water per day. Younger men consumed the most total water, but $42.7 \%$ consumed less than $3700 \mathrm{~mL}$ of water per day.

The second criterion of adequate hydration, water volume (in $\mathrm{mL}$ ) per $1000 \mathrm{kcal}$, did not fall short of desirable values, though such an evaluation is dependent on measuring energy intakes and expenditures accurately. Whereas the EFSA and IOM recommendations are at least $1.0 \mathrm{~L}$ per $1,000 \mathrm{kcal}[10,13]$, the observed values of $\sim 1.2-1.4 \mathrm{~L} / 1,000 \mathrm{kcal}$ were well above this cutpoint, though there were some differences by population sub-group. Women, non-Hispanic whites and adults with
Table 4 Total water and water density among adults by socio-demographic group

\begin{tabular}{|c|c|c|c|c|}
\hline & \multicolumn{2}{|c|}{$\begin{array}{l}\text { Total } \mathrm{H}_{2} \mathrm{O} \text { from all } \\
\text { sources }(\mathrm{mL})\end{array}$} & \multicolumn{2}{|c|}{$\begin{array}{l}\mathrm{H}_{2} \mathrm{O} \text { from all sources } \\
(\mathrm{mL}) \text { per } 1,000 \mathrm{kcal}\end{array}$} \\
\hline & $\begin{array}{c}\text { Mean } \\
(\mathrm{SE})\end{array}$ & $\begin{array}{c}\text { p-difference } \\
\text { of means }\end{array}$ & Mean (SE) & $\begin{array}{l}\text { p-difference } \\
\text { of means }\end{array}$ \\
\hline All adults & $3311(19)$ & - & $1369(5.4)$ & - \\
\hline \multicolumn{5}{|l|}{ Age group } \\
\hline $20-50 y$ & $3560(30)$ & ref & $1343(6.9)$ & ref \\
\hline $51-70 y$ & $3229(27)$ & $<0.001$ & $1442(12.3)$ & $<0.001$ \\
\hline$\geq 71 y$ & $2251(17)$ & $<0.001$ & $1306(11.7)$ & 0.14 \\
\hline \multicolumn{5}{|l|}{ Gender } \\
\hline Men & $3779(26)$ & ref & $1274(6.2)$ & ref \\
\hline Women & $2899(16)$ & $<0.001$ & $1454(9.3)$ & $<0.001$ \\
\hline \multicolumn{5}{|l|}{ Race/ethnicity } \\
\hline Non-Hispanic White & $3439(24)$ & ref & $1412(8.9)$ & ref \\
\hline Non-Hispanic Black & $2854(32)$ & $<0.001$ & $1185(10.2)$ & $<0.001$ \\
\hline Mexican-American & 3037 (36) & $<0.001$ & $1277(9.8)$ & $<0.001$ \\
\hline Other Hispanic & $3156(44)$ & $<0.001$ & $1308(11.1)$ & $<0.001$ \\
\hline $\begin{array}{l}\text { Other race - } \\
\text { including mixed race }\end{array}$ & $3155(67)$ & $<0.001$ & $1399(16.8)$ & 0.49 \\
\hline \multicolumn{5}{|l|}{$\begin{array}{l}\text { Family income-to- } \\
\text { poverty ratio }\end{array}$} \\
\hline$<1$ & $3164(37)$ & $<0.001$ & $1299(11.4)$ & $<0.001$ \\
\hline $1-1.99$ & $3176(27)$ & $<0.001$ & $1335(11.3)$ & $<0.001$ \\
\hline $2-3.49$ & $3172(30)$ & $<0.001$ & $1377(12.6)$ & 0.049 \\
\hline$\geq 3.5$ & $3512(23)$ & ref & $1411(11.8)$ & ref \\
\hline
\end{tabular}

higher family incomes tended to have diets that were more water dense.

The evaluation of water density suggests that water intake at the population-level is generally adequate, though evaluations of absolute values suggest that water intake may be too low among older adults. It is beyond the scope of this work to identify which of these two measures is the better indicator of water intake. Given the focus of the IOM DRIs Committee on the absolute intakes and the potential for under-estimating energy expenditure/intake, more emphasis should be placed on the absolute intake findings [13].

Biological markers, including serum or plasma osmolality, and to some extent urine osmolality, are additional markers of hydration status [10,33,34]. Until recently, hydration biomarkers were not included in NHANES data. In the 2009-2010 cycle, urine osmolality data were collected. Upon release of additional cycles that collect this data (to increase the sample size and availability of samples taken early in the morning), future work could examine patterns of this variable by population sub-group. However, no established cutoffs for hydration adequacy 
based on urine osmolality have been established at the population level.

The present analyses of the observed water intakes relative to the indices of hydration suggest that water consumption ought to be monitored more closely [35]. In 2010, EFSA published a 48-page report on water consumption, arguing that water is often disregarded in national and international recommendations or is very cursorily treated [10]. For example, the 2010 US Dietary Guidelines Advisory Group report devoted only two pages to water, stating that most healthy people consumed adequate water to meet their needs. Because water needs vary considerably, they concluded that a minimum intake of water could not be set [36].

The current study was unique in focusing on the consumption of plain drinking water and other beverages using the most recently available data for American adults. Previous work evaluating beverage intakes of adults has focused on the predictors and correlates of consuming specific beverages [37-40], the relation between beverage intake and measures of diet quality $[13,15,40]$, the contribution of beverages to nutrient or energy intake [41,42], or time-trends in beverage consumption patterns or preferences $[43,44]$. One important finding from the current study was differences in tap vs. bottled water consumption by socio-demographic factors, namely race/ethnicity, but also by family income. A recent study focused on the relation between the perceived safety of tap water and the intake of sugar sweetened beverages among US adults, nothing that those who viewed tap water as safe to drink tended to be older, have higher incomes, be better educated, were more active and were more likely to be white [45]. Water safety has previously been raised as a concern and may explain the higher proportion of MexicanAmerican and other Hispanics who consume bottled vs. tap water $[46,47]$. However, none of these studies measured water consumption directly. It is unclear why a weaker preference was observed for the non-Hispanic black population in the present study.

Another recent report, based on the 2007 National Cancer Institute's Food Attitudes and Behaviors Survey, examined behaviors and attitudes associated with low consumption of plain water among US adults [48]. Here, the adjusted odds of drinking $<4$ cups of water per day was associated with older age $(>55 \mathrm{y})$, sedentary lifestyles and low consumption of fruits and vegetables, but not with education or incomes. However, in this study regular water consumption was reported via questionnaire, not by measurement in a dietary recall or interview.

The present study therefore fills a gap in the existing knowledge regarding water consumption patterns among US adults. Although older adults are known to represent a group at risk, current data on water consumption patterns have not been available previously.
Future guidelines on beverage consumption should take plain drinking water into account. This is particularly important given the size of the shortfall between observed intakes and IOM AI values for older adults. This is particularly important given the increased likelihood of having an impaired thirst mechanism among older adults [49].

Total water intake can be increased in a number of ways. The most effective way would be to increase the consumption of plain water, including either tap or bottled water. Promoting water intake is currently highlighted in the 2010 Dietary Guidelines for Americans as a potential replacement for sugar-sweetened beverages [50]. Future dietary surveillance should monitor total water intake to determine if reducing intake of sugar-sweetened beverages has a negative impact on total water intake.

In the present analyses of NHANES 2005-2010 data, non-beverage food sources accounted for $17-25 \%$ of total dietary water, as compared to $19 \%$ reported in the 2010 Dietary Guidelines for Americans Advisory Committee report [36], though methods for assessing water intake have changed from previous NHANES cycles. This observation highlights that increasing consumption of low energy density foods with high water content foods (e.g., fruits/ vegetables) is another approach to increase water intakes, while subsequently improving overall diet quality.

The present analyses had some limitations. First, the NHANES data are based on self-report and are subject to random and systematic reporting errors. Each of the two dietary recall days used different methods to collect the data, which may introduce mode effects into the estimate of water consumption. If water intakes were under-reported in the NHANES database, then the estimates presented here will over-estimate the percent of adults who fail to meet the recommended intakes. It is probable that many respondents under-reported water intakes due to drinking water lacking salience. This may be particularly problematic for events where little water was consumed or it was consumed casually (e.g., repeatedly being refilled at a restaurant). It is important to note that these data cannot be directly compared to those from pervious cycles of NHANES (prior to 2005), as the mode for collecting data on water intake changed. In previous cycles of NHANES water intake was measured at the end of the recall via questionnaire, whereas in more recent cycles, water is measured as part of the 24hour recall. Comparisons of water intake for the entire population and population sub-groups between 19992004 and 2005-2006 reveal that estimated water intakes are approximately $15 \%$ lower using newer as compared to older data [15]. While this difference may be attributable to secular changes in water intake, they are more likely driven by changes in data collection. Caution should be applied when comparing the results presented here to data collected prior to 2005. An additional limitation in 
evaluating adequacy of water intake at the population-level is the lack of Recommended Daily Allowance values for water. While the AI values established by the IOM provide some benchmark in evaluating water intake, the proportions above/below this value should be interpreted cautiously. The 2010 Dietary Guidelines for Americans contends that the combination of thirst and normal eating/ drinking behaviors provides sufficient water [49]. Surveillance of water intake from dietary data should be carefully monitored and the use of biomarkers to evaluate hydration status at the population-level should be a priority.

Nonetheless, the present analyses represent one of the few explorations of the consumption of water in the US and can be used to inform approaches to improving the overall diet quality and hydration status of the population. Advantages of the data used here include the use of a large and nationally representative dataset that forms the basis for dietary surveillance in the US.

\section{Conclusions}

Among older men and women, there is evidence of inadequate water consumption in absolute terms. Fewer than $4.3 \%$ of men and $17.4 \%$ of women aged $\geq 71 y$ consumed the recommended amounts of total water. Increasing total water consumption can be achieved through various means, though promotion and encouragement of noncaloric beverages is likely to be the most successful avenue for increasing water consumption without increasing energy intakes.

\section{Abbreviations \\ DRI: Dietary reference intake; $\mathrm{NCl}$ : National Cancer Institute; \\ NHANES: National Health and Nutrition Examination Survey; IOM: Institute of}

Medicine; EFSA: European Food Standards Agency; Al: Adequate intake.

\section{Competing interests}

The authors declare that they have no competing interests.

\section{Authors' contributions}

AD and CDR designed the study. CDR analyzed the data. All authors and participated in drafting the manuscript. All authors read and approved the final manuscript.

\section{Acknowledgements}

This study was funded by Nestle Waters.

\section{Author details}

${ }^{1}$ Université Pierre et Marie Curie - Paris VI, Groupe Hospitalier Pitié-Salpêtrière, 47 boulevard de l'Hopital, Paris 75013, France. ${ }^{2}$ Center for Public Health Nutrition, University of Washington, Box 353410, Seattle, WA 98195, USA.

${ }^{3}$ Nestle Waters France12 boulevard Garibaldi, Issy-les-Moulineaux 92130, France.

Received: 28 May 2013 Accepted: 6 November 2013

Published: 12 November 2013

\section{References}

1. Armstrong LE: Hydration for health conference: paradigms and future directions. Nutr Today 2010, 45(6):S45-S46. Proceedings of the 1st hydration for health scientific meeting.

2. Campbell SM: Hydration needs throughout the lifespan. J Am Coll Nutr 2007, 26(5 Suppl):585S-587S.
3. Tate DF, Turner-McGrievy G, Lyons E, Stevens J, Erickson K, Polzien K, Diamond M, Wang X, Popkin B: Replacing caloric beverages with water or diet beverages for weight loss in adults: main results of the Choose Healthy Options Consciously Everyday (CHOICE) randomized clinical trial. Am J Clin Nutr 2012, 95(3):555-563.

4. Dennis EA, Dengo AL, Comber DL, Flack KD, Savla J, Davy KP, Davy BM: Water consumption increases weight loss during a hypocaloric diet intervention in middle-aged and older adults. Obesity (Silver Spring) 2010, 18(2):300-307.

5. Muckelbauer R, Sarganas G, Grüneis A, Müller-Nordhorn J: Association between water consumption and body weight outcomes: a systematic review. Am J Clin Nutr 2013, 98(2):282-299.

6. U.S. Centers for Disease Control: Low-energy-dense foods and weight management: cutting calories while controlling hunger. Research to practice series, No. 5. http://www.cdc.gov/nccdphp/dnpa/nutrition/pdf/ r2p_energy_density.pdf.

7. Stookey JD: Drinking water and weight management. Nutr Today 2010, 45(6):S7-S12.

8. Ello-Martin JA, Roe LS, Ledikwe JH, Beach AM, Rolls BJ: Dietary energy density in the treatment of obesity: a year-long trial comparing 2 weight-loss diets. Am J Clin Nutr 2007, 85(6):1465-1477.

9. Drewnowski A: Energy density, palatability and satiety: implications for weight control. Nutr Rev 1998, 56:347-353.

10. European Food Safety Association: EFSA Panel on Dietetic Products, Nutrition, and Allergies (NDA); Scientific Opinion on Dietary reference values for water. EFSA Journal 2010, 8(3):1459 [48 pp.]. [http://www.efsa. europa.eu/en/efsajournal/pub/1459.htm].

11. Armstrong LE, Maresh CM, Castellani JW, Bergeron MF, Kenefick RW, LaGasse KE, Riebe D: Urinary indices of hydration status. Int J Sport Nutr 1994, 4:265-279.

12. Manz F, Wentz A, Sichert-Hellert W: The most essential nutrient: defining the adequate intake of water. J Pediatr 2002, 141(4):587-592.

13. Institute of Medicine: Dietary Reference Intakes for Water, Potassium, Sodium, Chloride, and Sulfate. Washington, D.C.: National Academies Press; 2004.

14. Duffey KJ, Popkin BM: Adults with healthier dietary patterns have healthier beverage patterns. J Nutr 2006, 136(11):2901-2907.

15. Kant AK, Graubard BI, Atchison EA: Intakes of plain water, moisture in foods and beverages, and total water in the adult US population-nutritional, meal pattern, and body weight correlates: National Health and Nutrition Examination Surveys 1999-2006. Am J Clin Nutr 2009, 90(3):655-663.

16. Park S, Blanck HM, Sherry B, Brener N, OToole TJ: Factors associated with low water intake among US high school students - National Youth Physical Activity and Nutrition Study, 2010. Acad Nutr Diet 2012, 112(9):1421-1427.

17. Fulgoni VL 3rd: Limitations of data on fluid intake. J Am Coll Nutr 2007, 26(5 Suppl):588S-591S.

18. Sohn W, Heller KE, Burt BA: Fluid consumption related to climate among children in the United States. J Public Health Dent 2001, 61(2):99-106.

19. Centers for Disease Control and Prevention: National Health and Nutrition Examination Survey (NHANES): NCHS Research Ethics Review Board (ERB) Approval. http://www.cdc.gov/nchs/nhanes/irba98.htm.

20. Centers for Disease Control and Prevention: National Health and Nutrition Examination Survey (NHANES): questionnaires, datasets, and related documentation. http://www.cdc.gov/nchs/nhanes/nhanes_questionnaires.htm.

21. Centers for Disease Control and Prevention: National Health and Nutrition Examination Survey (NHANES): MEC in-person dietary interviewers procedures manual. http://www.cdc.gov/nchs/data/nhanes/nhanes_05_06/ dietary_mec.pdf.

22. Centers for Disease Control and Prevention: National Health and Nutrition Examination Survey (NHANES): phone follow-up dietary interviewer procedures manual. [http://www.cdc.gov/nchs/data/nhanes/nhanes_05_06/ DIETARY_PFU.pdf.

23. Centers for Disease Control and Prevention: National Health and Nutrition Examination Survey (NHANES): dietary interview component. http://www. cdc.gov/nchs/data/nhanes/nhanes_05_06/dietaryrecall_d.pdf.

24. Centers for Disease Control and Prevention: National Health and Nutrition Examination Survey (NHANES): 2005-2006 dietary interview documentation. http://www.cdc.gov/nchs/nhanes/nhanes2005-2006/ DRXDOC_D.htm\#Protocol_and_Procedure.

25. Tooze JA, Midthune D, Dodd KW, Freedman LS, Krebs-Smith SM, Subar AF, Guenther PM, Carroll RJ, Kipnis V: A new statistical method for estimating the usual intake of episodically consumed foods with application to their distribution. J Am Diet Assoc 2006, 106(10):1575-1587. 
26. Tooze JA, Kipnis V, Buckman DW, Carroll RJ, Freedman LS, Guenther PM, Krebs-Smith SM, Subar AF, Dodd KW: A mixed-effects model approach for estimating the distribution of usual intake of nutrients: the $\mathrm{NCl}$ method. Stat Med 2010, 29(27):2857-2868.

27. Krebs-Smith SM, Kott PS, Guenther PM: Mean proportion and population proportion: two answers to the same question? J Am Diet Assoc 1989 89(5):671-676.

28. National Cancer Institute, Applied Research: Usual dietary intakes: the NC method. http://appliedresearch.cancer.gov/diet/usualintakes/method.html.

29. Centers for Disease Control and Prevention: Advanced dietary analyses. http://www.cdc.gov/nchs/tutorials/dietary/advanced/.

30. Jéquier $E$, Constant F: Water as an essential nutrient: the physiological basis of hydration. Eur J Clin Nutr 2010, 64(2):115-123.

31. Kenefick RW, Cheuvront SN: Hydration for recreational sport and physical activity. Nutr Rev 2012, 70(Suppl 2):S137-S142.

32. Sawka MN, Cheuvront SN, Carter R 3rd: Human water needs. Nutr Rev 2005, 63(6, Pt 2):S30-\$39.

33. Armstrong LE: Assessing hydration status: the elusive gold standard. J Am Coll Nutr 2007, 26(5 Suppl):575S-584S.

34. Perrier $E$, Vergne $S$, Klein A, Poupin M, Rondeau P, Le Bellego L, Armstrong $L E$, Lang F, Stookey J, Tack I: Hydration biomarkers in free-living adults with different levels of habitual fluid consumption. Br J Nutr 2013, 109(9):1678-1687.

35. Grandjean AC, Reimers KJ, Buyckx ME: Hydration: issues for the 21st century. Nutr Rev 2003, 2003(61):261-271.

36. U.S. Department of Agriculture, Center for Nutrition Policy and Promotion: Report of the dietary guidelines advisory committee on the dietary guidelines for Americans. 2010. http://www.cnpp.usda.gov/DGAs2010DGACReport.htm.

37. Park S, Onufrak S, Blanck HM, Sherry B: Characteristics associated with consumption of sports and energy drinks among US adults: National Health Interview Survey, 2010. J Acad Nutr Diet 2013, 113(1):112-119.

38. Popkin BM: Patterns of beverage use across the lifecycle. Physiol Behav 2010, 100(1):4-9

39. Storey ML, Forshee RA, Anderson PA: Beverage consumption in the US population. J Am Diet Assoc 2006, 106(12):1992-2000.

40. Bowman SA: Beverage choices of young females: changes and impact on nutrient intakes. J Am Diet Assoc 2002, 102(9):1234-1239.

41. Popkin BM, Barclay DV, Nielsen SJ: Water and food consumption patterns of U.S. adults from 1999 to 2001. Obes Res 2005, 13(12):2146-2152.

42. Garriguet D: Beverage consumption of Canadian adults. Health Rep 2008 19(4):23-29.

43. Nielsen SJ, Popkin BM: Changes in beverage intake between 1977 and 2001. Am J Prev Med 2004, 27(3):205-210.

44. Storey M: The shifting beverage landscape. Physiol Behav 2010, 100(1):10-14.

45. Onufrak SJ, Park S, Sharley JR, Sherry B: The relationship of perceptions of tap water safety with intake of sugar-sweetened beverages and plain water among US adults. Public Health Nutr 2012, 26:1-7.

46. Hobson WL, Knochel ML, Byington CL, Young PC, Hoff CJ, Buchi KF: Bottled, filtered, and tap water use in Latino and non-Latino children. Arch Pediatr Adolesc Med 2007, 161(5):457-461.

47. Huerta-Saenz L, Irigoyen M, Benavides J, Mendoza M: Tap or bottled water: drinking preferences among urban minority children and adolescents. $J$ Community Health 2012, 37(1):54-58.

48. Goodman AB, Blanck HM, Sherry B, Park S, Neneling L, Yaroch AL: Behaviors and attitudes associated with low drinking water intake among US adults, food attitudes and behaviors survey 2007. Prev Chronic Dis 2013, 10:E51.

49. Rolls BJ, Phillips PA: Aging and disturbances of thirst and fluid balance. Nutr Rev 1990, 48(3):137-144.

50. U.S. Department of Agriculture and U.S. Department of Health and Human Services: Dietary Guidelines for Americans. 2010. http://www.cnpp.usda. gov/dietaryguidelines.htm.

doi:10.1186/1471-2458-13-1068

Cite this article as: Drewnowski et al:: Water and beverage consumption among adults in the United States: cross-sectional study using data from NHANES 2005-2010. BMC Public Health 2013 13:1068.

\section{Submit your next manuscript to BioMed Central and take full advantage of:}

- Convenient online submission

- Thorough peer review

- No space constraints or color figure charges

- Immediate publication on acceptance

- Inclusion in PubMed, CAS, Scopus and Google Scholar

- Research which is freely available for redistribution

Submit your manuscript at www.biomedcentral.com/submit
C BioMed Central 